medicine or the physician this book would not go far enough.

Many illustrative electrocardiographic tracings are given and some useful notes on the clinical aspects of the disorders. Although the practitioner is encouraged to diagnose the arrhythmias at the bedside, he is not expected to hear atrial sounds, count venous waves in the neck, or be deluded into thinking that he should always be able to distinguish atrial fibrillation from multiple ectopic beats without an electrocardiograph.

Practical notes on treatment are given with each section. However, one views with disquiet the type of medical practitioner for whom this book is designed, using many of the reversion techniques, when without a good deal of experience. The American general practitioner may have more opportunity for using such drugs as quinidine and procainamide, but his British counterpart sees little of his patient's treatment in hospital.

Thus to the practitioner who wishes to know more of arrhythmias without becoming involved in electrocardiography this book will appeal.

\section{The Anatomy of the Eye and Orbit}

Eugene WolfF. Fifth edition. Revised by R. J. LAST, M.B., B.S., F.R.C.S.ENG. 438 illustrations (54 coloured). Pp. viii +500 , London: H. K. Lewis. $£ 44$ s.

This book was first published in 1933 and following the death of Eugene Wolff the fifth edition has been revised by Professor R. J. Last. It presents a clear account of the macroscopic and microscopic structure, development and comparative anatomy of the visual apparatus. With advances in technique and the introduction of the electron microscope anatomy is a growing subject.

There are some omissions in the book, such as recent work on the oculo-motor nucleus and the blood supply of the optic nerve head.

The book is well produced and richly illustrated. Most of the author's original black and white drawings have been retained.

Professor Last has preserved the spirit and pattern of the original work and it can be highly recommended to students of ophthalmology and to those interested in the anatomy of the visual apparatus.

\section{Essentials of Neurology}

John N. Walton, M.D., M.R.C.P. Pp. xvii +422 , illustrated. London: Pitman Medical Publishing Co. 196r. 30 s.

The need for a brief text book of neurology has been felt for some time but it is not certain, however, that the need has been completely fulfilled. Dr. Walton's book is intended for undergraduate and postgraduate students, and for practitioners. Compression has been achieved partly by limiting the scope of the work, which is written from the standpoint of the bedside neurologist. Accounts of normal and disordered physiology, and of pathology, have largely been omitted and are only mentioned when 'absolutely necessary for an understanding of clinical principles '. Nevertheless, the book is, in general, remarkably comprehensive. An exception is the chapter on psychiatric disorders which is so sketchily written that its inclusion seems hardly profitable. The reviewer also objects, on semantic grounds, to its entitlement as 'Disorders of the Mind'.

With regard to the general plan of the book, Dr. Walton begins by considering some useful general principles, and follows this by chapters on the investigation of the neurological patient. The remainder of the first half of the book consists of an analysis of the principal symptoms and signs produced by diseases of the nervous system. In the second half, he presents a description of individual diseases and syndromes and concludes with a chapter, perhaps a little too abbreviated, on treatment in neurology. The style is fluent, making the work surprisingly readable in view of the condensation of material that has been achieved.

Dr. Walton's 'Essentials of Neurology' represents a useful addition to the teaching of neurology.

Advances in Biology of Skin: Vol. I-Cutaneous Innervation

Edited by William Montagna. Pp. xii +203 , with 118 illustrations. Oxford, London, New York, Paris: Pergamon Press. 1960. 63 s.

This publication represents the proceedings of the Brown University Symposium on the Biology of the Skin held in 1959. Recent years have yielded innervation as newer histological and electrophysiological techniques have been applied. The participants in this symposium include several of those who have contributed to these advances.

Accounts of the histological aspects of cutaneous innervation have been provided by Malcolm Miller and his associates, R. K. Winkelmann and William Montagna. The high quality of the photographic plates illustrating these articles is to be commended. The changes in knowledge of cutaneous neurohistology that have accrued over the past two decades have given rise to problems concerning the mechanism of cutaneous sensibility. Fxperiments relating to a possible solution are described by Graham Weddell. There are also two chapters by G. H. Bishop on the relation of nerve fibre size to modality of sensation and to the organization of the central paths of the cutaneous afferents, which are an interesting synthesis of physiological and anatomical studies. Other articles are on autonomic innervation and on the mechanism of itch.

Although much of the material included has been published elsewhere, this book provides a useful compilation of recent work in this important field.

\section{The Practical Management of Head Injuries}

John M. PotTer, M.A., M.B., B.CHIR.(CANTAB.), F.R.C.s. Pp. xii +84 , illustrated. London: LloydLuke (Medical Books). I96 I. I2s.

This short account of the management of head injuries begins by considering the examination and assessment of the patient in the casualty department and follows with an account of care in the ward. A chapter is devoted to the treatment of complications and finally one to the important question of rehabilitation after head injuries. It is lucidly written in an informal and engaging style. The author has undoubtedly succeeded in providing a book that, to quote from the preface, is ' a practical guide . . . not designed to help those who merely wish to pass surgical examinations '.

\section{A Manual of Psychiatry}

K. R. Stallworthy, M.B., Ch.B., Diploma Psychological Medicine. Fifth edition. Pp. 386. Christchurch, New Zealand: N. M. Peryer. 1961. 305.

Both Dr. Stallworthy and the writer of the foreword suggest that this 'Manual of Psychiatry' is suitable for students, general practitioners and nurses. This is not so. It might possibly suffice to acquaint a long-established general practitioner whose psychiatric education had been neglected as an undergraduate with the 